\title{
Ocular Morbidity among Children Attending Government and Private Schools of Kathmandu Valley
}

\author{
Shrestha RK¹, Joshi $M R^{2}$, Ghising R¹, Rizyal $A^{1}$ \\ ' Department of Ophthalmology, Nepal Medical College Teaching Hospital, Jorpati, Kathmandu, Nepal, ${ }^{2}$ Department of \\ Optometry and Vision Science, Hogskolen I Buskerud, Kongsberg, Norway.
}

\section{ABSTRACT}

Introduction: Children from the developing world are more prone to going blind from avoidable and preventable causes. In Nepal, children in private schools are reported to have a higher ocular morbidity than those in government schools, with myopia being the major cause of the morbidity. This study was designed to evaluate ocular morbidity in students from both types of school.

Method: This was a cross-sectional, comparative study among students from government and private schools of Kathmandu. Eye examination was carried out evaluating visual acuity, color vision, refractive status, binocular vision status, and anterior and posterior segment findings.

Results: A total of 4,228 students from government and private schools were evaluated. The prevalence of ocular morbidity was $19.56 \%$ with refractive error $(11.9 \%)$ being the major cause of the morbidity, followed by strabismus and infective disorders. No significant difference in the prevalence of ocular morbidity and refractive status was found in the students from government and private schools.

Conclusion: A significant number of children of school-going age have ocular morbidity with no significant difference in the prevalence in the students from government and private schools. Research exploring the effect of various risk factors in the progression of myopia would be helpful to investigate the refractive status in children from these different types of schools.

Keywords: Myopia, ocular morbidity, school students

\section{INTRODUCTION}

Among the estimated 1.4 million blind children globally, $75 \%$ live in developing countries. ${ }^{1}$ The prevalence of childhood blindness is four-fold higher in the poorer $(1.2 / 1,000)$ than in the wealthy regions $(0.3 / 1,000) .^{2}$ As blind children remain blind for the rest of the life without intervention, childhood blindness is the second most common cause of blind person years, second only to cataract. Due to the large magnitude of childhood blindness, it has been recognized as one of the major challenges of Vision 2020, "The Right to Sight". Most of the cases of childhood blindness in the developing world are avoidable, preventable and treatable. ${ }^{3}$
Among the 5.5 million children in Nepal (below 16 years), about 3.7 million are of school-going age (5-16 years). ${ }^{4}$ Various studies from different parts of Nepal have reported different patterns of ocular morbidity among children of school-going age. In a study of children from government schools in Kathmandu, $11 \%$ of the children had ocular morbidity, $97 \%$ of which was preventable or treatable ${ }^{5}$, whereas a much

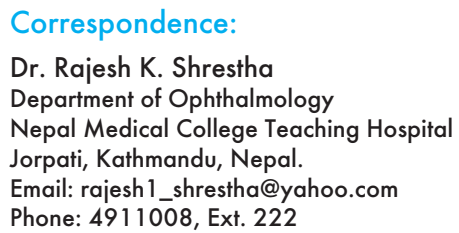


higher prevalence (34\%) has been reported in children from private schools. ${ }^{6}$ Various studies have reported uncorrected refractive error to be an important cause of visual impairment in Kathmandu. ${ }^{(6,7)}$ Similarly, a study on refractive error from a different part of Nepal has reported a significantly higher prevalence of refractive error in children of private schools than in those from government schools, which was attributed to a higher study load on students from private schools. ${ }^{8}$

Government schools differ from private schools in terms of resources, modes of teaching-learning activities and the overall study load to the students. The academic output of the private school is also better than the government schools as seen in the annual School Leaving Certificate (SLC) results. Children of parents from a better socioeconomic status also prefer the private schools to the state run schools. ${ }^{9}$

Discrepancy in the socio economic status of children and the study load and time spent on extracurricular activities could have a detrimental effect on the progression of refractive error, infective disease. and other ocular morbidities.

This study was hence designed to find out the pattern of morbidity in children of government and private schools of Kathmandu Valley.

\section{METHODS}

Various government $(n=5)$ and private school $(n=4)$ students from different urban and semi-urban areas of Kathmandu were purposively selected. The selection was made so that for each government school selected, a private school from nearby was also selected. The selection was based on the accessibility and willingness of the school authorities to participate in the study, among other factors. The school authorities and parents were pre-informed about the study and its potential advantages and disadvantages. All willing students from grade one to ten of the selected schools were included in the study. Ethical approval was obtained from the Institutional Research/Review Committee of Nepal Medical College Teaching Hospital prior to the commencement of study. A team of ophthalmologists, optometrists, and ophthalmic assistants visited each school for the ocular evaluations.

\section{Examination methods}

The standard examination method was used for the ocular evaluations. Visual acuity was measured with internally - illuminated Snellen's chart. Color vision was screened with the help of Isihara pseudo-isochromatic plates, 38 plates edition. The child was diagnosed as having color vision defect if the child made mistakes in identifying four or more plates of the chart.

Extra ocular motility was recorded in nine positions of gaze. The cover test was used to assess the binocular vision function. Any detectable movement on the alternate cover test was recorded as phoria. The Royal Army Force (RAF) gauze was used to measure the near point of convergence and the amplitude of accommodation. Both convergence and accommodation were measured three consecutive times and the average of the findings was recorded.The prism fusion range for near at $40 \mathrm{~cm}$ was evaluated with the prism bar and only the break point was recorded. The positive and negative fusional vergence was measured. Convergence, accommodation and prism fusion range range measured binocularly and only those who had binocular single vision and ocular health which did not interfere with binocular vision were evaluated.

Retinoscopy and subjective refraction were performed to come up with the best-corrected visual acuity. Whenever necessary, cycloplegic refraction was carried out 15 minutes after installing Cyclopentolate $1 \%$ eye drop, and the extent of cycloplegia was confirmed by observing the ability of the child to read small prints. Cyclorefraction was done when there was any confusion regarding the objective retinoscopy, for the error of more than +0.75 hypermetropia and when there was no improvement upon subjective refraction in the absence of any ocular findings correlating to reduced vision.

Haag Streit Slit lamp with 90D lens for direct ophthalmoscope was used to evaluate the anterior and posterior segments in all children. All the findings were recorded in a proforma. The diagnosis of myopia and hyperopia was made when the spherical equivalent was 0.25 dioptres or more. The diagnosis of amblyopia was made if visual acuity was worse than 6/9 after meticulous refraction in the absence of any ocular pathology. The diagnosis of strabismic amblyopia was made if the reduced visual acuity was due to the strabismus. Similarly, the diagnosis of refractive amblyopia was made if there was anisometropia of 1.00 dioptre of hypermetropia or 4 dioptres of myopia. The students that required further evaluation and treatment were referred to the base hospital. After evaluation, all findings were recorded in an Excel spreadsheet. Data analysis was done on Microsoft Excel and Stat Plus statistical software.

\section{RESULTS}

The aim was to evaluate 5000 students from the two types of schools. However, due to logistical and other 
reasons, a total of 4228 students, 2282 from the government and 1946 from the private schools were examined. The age of the students was between 4 to 20 years with the mean age of 12.13 . The demographic distribution is given in Figure 1 and Table 1.

\section{Gender distribution of the children}

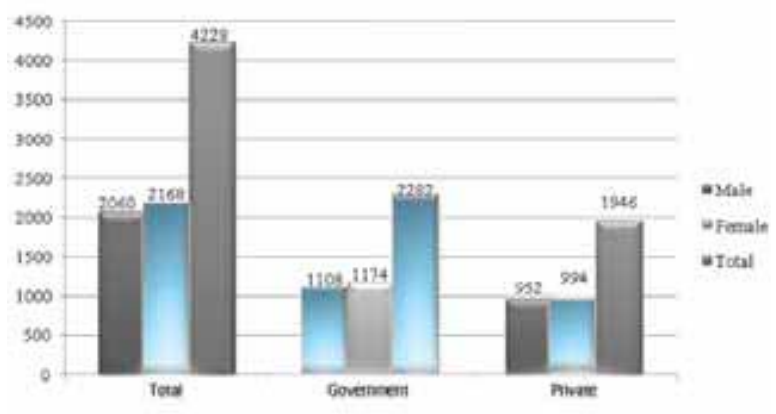

Figure 1. Gender distribution of the children

Table 1. Age distribution of the children

\begin{tabular}{llll}
\hline Age (years) & Total & Government & Private \\
\hline Mean & 12.3 & $12.47(4-19)$ & $12.13(4-20)$ \\
Mean age (Male) & 12.31 & 12.40 & 12.22 \\
\hline Mean age (Female) & 12.29 & 12.55 & 12.04 \\
\hline
\end{tabular}

Visual acuity and color vision

More than $90 \%$ of children had a presenting visual acuity of $6 / 6$ in both the right and left eye. Six children in the right eye and five children in the left eye had severe visual impairment $(<6 / 60)$ but none had severe impairment in both eyes. The mean decimal visual acuity was 0.946 in the right and the left eye for children from government schools. For children from private schools, the mean visual acuity was 0.944 for both eyes. the detailed distribution of visual acuity is given in Table 2 . The prevalence of congenital color vision defect was 1 . $37 \%(n=58)$ among all the children. All the affected children were male hence among the male, children the prevalence was 2. $81 \%$ (58 out of 2060). Among the different types of color vision defect detected by the Ishihara color plates, the most common was strong deutran ( $N=46$ ), followed by total color blindness ( $n$ $=6)$, mild deutan $(n=4)$ and mild protan $(n=2)$.

\section{Binocular vision status}

About $86 \%$ of children in both the types of schools were orthophoric and $11 \%$ had phorias. The prevalence of various types of strabismus was $3.18 \%$. Exortopia was present in $2.88 \%$ while esotropia in $0.24 \%$. The binocular vision status is given in Table 3. Among the 4002 children who were examined for convergence and accommodation, the mean near point of convergence was $7.18 \mathrm{~cm}$. The mean amplitude of accommodation was $7.27 \mathrm{~cm}$. The mean break point of prism fusion range at $40 \mathrm{~cm}$ was 25.76 dioptres base out and 9.67 dioptres base in.

Table 2. Distribution of presenting visual acuity

\begin{tabular}{|lll|}
\hline Visual Acuity & RE & LE \\
$6 / 6-6 / 18$ & 4102 & 4092 \\
$<6 / 18-6 / 60$ & 120 & 131 \\
$<6 / 60-3 / 60$ & 1 & 1 \\
$<3 / 60-1 / 60$ & 2 & 2 \\
\hline $1 / 60-P L$ & 3 & 2 \\
\hline NPL & 0 & 0 \\
\hline Total & 4228 & 4228 \\
\hline $6 / 6$ & $3810(90.11 \%)$ & $3819(90.32 \%)$ \\
\hline
\end{tabular}

Table 3. Binocular vision status of the children

\begin{tabular}{|c|c|c|c|}
\hline Status & Total (\%) & $\begin{array}{c}\text { Government } \\
\text { (\%) }\end{array}$ & Private (\%) \\
\hline Orthophoria & $3626(85.78)$ & 1958 (85.79) & 1669 (85.76) \\
\hline Exophoria & $457(10.81)$ & 245 (10.74) & 212 (10.89) \\
\hline Esophoria & $9(0.21)$ & $5(0.22)$ & $4(0.20)$ \\
\hline $\begin{array}{l}\text { Intermittent } \\
\text { Exotropia }\end{array}$ & $62(1.47)$ & $26(1.14)$ & $36(1.85)$ \\
\hline $\begin{array}{l}\text { Right } \\
\text { Exotropia }\end{array}$ & $3(0.071)$ & $2(0.087)$ & $1(0.051)$ \\
\hline $\begin{array}{l}\text { Left } \\
\text { Exotropia }\end{array}$ & $9(0.21)$ & $8(0.35)$ & $1(0.051)$ \\
\hline $\begin{array}{l}\text { Right } \\
\text { Esotropia }\end{array}$ & $5(0.12)$ & $4(0.17)$ & $1(0.051)$ \\
\hline $\begin{array}{l}\text { Left } \\
\text { Esotropia }\end{array}$ & $0(0)$ & $0(0)$ & $0(0)$ \\
\hline $\begin{array}{l}\text { Alternate } \\
\text { divergent } \\
\text { squint }\end{array}$ & $48(1.13)$ & $30(1.31)$ & $18(0.92)$ \\
\hline $\begin{array}{l}\text { Alternate } \\
\text { convergent } \\
\text { squint }\end{array}$ & $5(0.12)$ & $2(0.087)$ & $3(0.15)$ \\
\hline $\begin{array}{l}\text { Duanes } \\
\text { syndrome }\end{array}$ & $3(0.07)$ & $2(0.087)$ & $1(0.051)$ \\
\hline Total & 4227 & 2282 & 1946 \\
\hline
\end{tabular}


Shrestha et al. Ocular Morbidity among Children Attending Government and Private School of Kathmandu Valley

\section{Refractive Status}

The prevalence of refractive error was $11.09 \%$ among all students, $10.6 \%$ in the government schools and $11.66 \%$ in the private schools. Among the students at government schools $9.29 \%(n=212)$ were myopic and $1.31 \%(\mathrm{n}=30)$ hyperopic. Similarly, at private schools, $10.17 \%(\mathrm{n}=198)$ were myopic and $1.49 \%$ ( $\mathrm{n}=29$ ) hyperopic.

The mean spherical equivalent refractive error among the total government-school students was - 0.131 and -0.136 in the right and left eye respectively. Similarly, for private schools the mean refractive error was -0.14 and -0.141 in the right and left eye respectively. The highest myopic finding was - 14.50 in government school students and -11.00 in private schools. The distribution of refractive error in the right eye and left eye is given in Table 4.

Table 4. Distribution of the refractive error

\begin{tabular}{|lllll|}
\hline \multirow{2}{*}{$\begin{array}{l}\text { Power } \\
\text { (Sph. equivalent) }\end{array}$} & \multicolumn{2}{l}{ Government } & \multicolumn{2}{l|}{ Private } \\
\cline { 3 - 4 } & $\mathrm{RE}$ & $\mathrm{LE}$ & $\mathrm{RE}$ & $\mathrm{LE}$ \\
-0.25 to -2.00 & 170 & 173 & 149 & 154 \\
\hline-2.25 to -4.00 & 27 & 26 & 33 & 31 \\
\hline-4.25 to -6.00 & 9 & 9 & 10 & 10 \\
\hline$>-6.00$ & 4 & 4 & 3 & 3 \\
\hline 0.00 & 2042 & 2043 & 1725 & 1719 \\
+0.25 to +2.00 & 28 & 27 & 23 & 25 \\
\hline+2.25 to +4.00 & 1 & 0 & 1 & 1 \\
\hline$>+4.00$ & 1 & 0 & 2 & 3 \\
\hline Total & 2282 & 2282 & 1946 & 1946 \\
\hline
\end{tabular}

There was no significant difference in the refractive status of children from the two types of schools in both the right eye $(p=0.546)$ and left eye $(p=0.84)$. There were more myopic female children $(10.33 \%$, $\mathrm{n}=2168)$ than myopic male $(9.61 \%, \mathrm{n}=2060)$ and there was a similar percentage of hyperopic females $(1.43 \%)$ and males (1.41\%). Statistically there was no significant difference in the refractive error among the total male and female children in each eye $(p>0.05)$.

\section{Distribution of ocular morbidity}

Out of the 4227 students evaluated, 827 (19, $56 \%$ ) were found to have some form of ocular morbidity. A total of $428(18.75 \%)$ children from government schools had some form of ocular morbidity with 28 children diagnosed with two disorders. In private schools, 399 (20.5\%) children had some form of ocular morbidity with 19 children having a combination of two disorders. The total distribution of various ocular disorders is given in Table 5 .
Table 5. Distribution of different ocular morbidity

\begin{tabular}{|c|c|c|c|}
\hline & Total & Government & Private \\
\hline Diagnosis & $\begin{array}{l}\text { Number (\%) } \\
(n=4227)\end{array}$ & $\begin{array}{l}\text { Number }(\%) \\
(n=2282)\end{array}$ & $\begin{array}{l}\text { Number } \\
(\%) \\
(n=1946)\end{array}$ \\
\hline Refractive error & 469 (11.09) & $242(10.60)$ & $227(11.66)$ \\
\hline Strabismus & $135(3.19)$ & $74(3.24)$ & $61(3.13)$ \\
\hline $\begin{array}{l}\text { Infective } \\
\text { disorder }\end{array}$ & $63(1.49)$ & $25(1.09)$ & $38(1.95)$ \\
\hline $\begin{array}{l}\text { Convergence } \\
\text { Insufficiency }\end{array}$ & $37(0.87)$ & $13(0.57)$ & $24(1.23)$ \\
\hline $\begin{array}{l}\text { Congenital } \\
\text { color vision } \\
\text { defect }\end{array}$ & $58(1.37)$ & $36(1.57)$ & $22(1.13)$ \\
\hline $\begin{array}{l}\text { Glaucoma } \\
\text { Suspect }\end{array}$ & $32(0.76)$ & $18(0.79)$ & $14(0.72)$ \\
\hline Dry Eye & $32(0.76)$ & $20(0.88)$ & $12(0.62)$ \\
\hline $\begin{array}{l}\text { Congenital } \\
\text { Disorders }\end{array}$ & $17(0.40)$ & $12(0.52)$ & $5(0.26)$ \\
\hline $\begin{array}{l}\text { Corneal } \\
\text { Opacity }\end{array}$ & $6(0.142)$ & $2(0.087)$ & $4(0.20)$ \\
\hline Amblyopia & $6(0.142)$ & $3(0.13)$ & $3(0.15)$ \\
\hline Cataract & $4(0.09)$ & $2(0.088)$ & $2(0.10)$ \\
\hline $\begin{array}{l}\text { Adherent } \\
\text { Leucoma }\end{array}$ & $1(0.02)$ & $0(0)$ & $1(0.051)$ \\
\hline $\begin{array}{l}\text { Vitamin A } \\
\text { deficiency } \\
\text { (Bitot's spot) }\end{array}$ & $2(0.05)$ & $1(0.044)$ & $1(0.051)$ \\
\hline $\begin{array}{l}\text { Juvenille } \\
\text { Open Angle } \\
\text { Glaucoma }\end{array}$ & $1(0.02)$ & $0(0)$ & $1(0.051)$ \\
\hline Proptosis & $2(0.05)$ & $1(0.044)$ & $1(0.051)$ \\
\hline $\begin{array}{l}\text { Atrophic and } \\
\text { Pthisis Bulbi }\end{array}$ & $3(0.07)$ & $2(0.088)$ & $1(0.051)$ \\
\hline $\begin{array}{l}\text { Retinitis } \\
\text { Pigmentosa }\end{array}$ & $1(0.02)$ & $0(0)$ & $1(0.051)$ \\
\hline Nystagmus & $2(0.05)$ & $2(0.088)$ & $0(0)$ \\
\hline $\begin{array}{l}\text { Old Retinal } \\
\text { Detachment }\end{array}$ & $2(0.05)$ & $2(0.088)$ & $0(0)$ \\
\hline Kertaoconus & $1(0.02)$ & $1(0.044)$ & $0(0)$ \\
\hline Total & 874 & 456 & 418 \\
\hline
\end{tabular}


The commonest causes of the two disorders in the children were refractive error and infective disorders in both government (13 out 28) and private (8 out of 19) schools. Refractive error was a major cause of morbidity in both types of schools, followed by strabismus. The third cause was infective disorders including blepharitis, meibomitis and conjunctivitis. Congenital disorders accounted for $0.40 \%(n=17)$ of the total cases. of the congenital disorders, conjunctival naevus was the most common of the total number of students ( $\mathrm{n}=$ $9)$, followed by ptosis $(n=4)$. Similarly, amblyopia accounted for 6 cases $(0.142 \%)$ with the majority of cases being refractive in nature $(n=5)$ while only one child had starbismic amblyopia due to esotropia.

\section{DISCUSSION}

The prevalence of ocular morbidity was $19.56 \%$ among the total number of school children of our study, $18.75 \%$ in the government and $20.5 \%$ in the private schools. The prevalence of ocular morbidity has been reported to be $11 \%$ and $34.2 \%$ in government and private school of Kathmandu Valley respectively. ${ }^{5,6}$ In the previous studies, the government schools were selected from mainly the rural areas of Kathmandu while the private schools were from urban areas. However, in this study, both the government and private schools were selected from similar areas, the urban and semiurban areas of Kathmandu, which may be the reason why the prevalence is similar for both types of schools. A study from North India also reported no significant difference in the overall prevalence of ocular morbidity in government and private schools. ${ }^{14}$ Different patterns and prevalences of ocular morbidity have been reported from various studies in different parts of the world. In India, the prevalence of ocular morbidity was $31.6 \%$ among children of 6 to 16 years of age. ${ }^{14}$ However, in a study from Nigeria, among school children of 4 to 14 years, the prevalence of ocular diseases was $15.5 \%{ }^{15}$

Refractive error was found to be the most important cause of ocular morbidity accounting for $11.09 \%$ of the total students. Myopia was the most common cause of refractive error. Studies have shown refractive error to be the most prevalent form of ocular morbidity and myopia to be most common type of refractive error. ${ }^{6,14,16,17}$ The prevalence of refractive error in spherical equivalence was $10.6 \%$ in government schools and $11.66 \%$ in private schools. A similar study from Kathmandu has reported $8.1 \%{ }^{5}$ and 21.9 $\%{ }^{6}$ of morbidity due to refractive error in government and private schools. A cross-sectional study from western Nepal has reported a significantly higher refractive error in private schools as compared to government ones and this has been attributed to the higher educational load in private schools. ${ }^{8}$ However, no such significant difference in refractive error was found in the present study. In a study from North India, there was no significant difference in the prevalence of refractive error in government schools (21.5\%) and private schools $(22.6 \%) .{ }^{14}$ A study from Karachi reported the prevalence of refractive error to be $8.9 \%$ with no association with class, age, ethnicity, parental education and other risk factors. ${ }^{11}$ Other studies have reported the vulnerability of an urban population to refractive error as compared to a rural population. ${ }^{19,21}$ Another possible explanation for a significantly high refractive error in private schools as reported in other studies could be due to the change in the rural/urban setting in addition to the reported more near-work load. As in this study, since schools from both government and private schools were selected from similar areas, the effect due to the rural/urban setting might not have been detected. The differences in the prevalence of refractive error could also be due to the different diagnostic criteria used by the different studies.

The prevalence of any phoria was $11 \%$. This low prevalence found in the study could be due to the fact that the evaluation were carried out in a community setting, with poor lighting conditions. This might have resulted in small phorias remaining undetected. Strabismus was the second most common cause of morbidity with exotropia (2.88 \%) being more common than esotropia $(0.24 \%)$. The study of government schools of Nepal reported a lower prevalence of strabismus (1.63\%), however, the prevalence of divergent squint was higher than the convergent squint as in the present study. ${ }^{5}$ A study in Iran reported 2.02 $\%$ of children with strabismus, with the prevalence of exotropia and esotropia being $1.30 \%$ and $0.59 \%$ respectively. ${ }^{18}$ In India, the prevalence of squint was $2.5 \% .^{14}$ The prevalence of amblyopia was $0.14 \%$, the low prevalence of amblyopia in this study could be because the study was carried out in Kathmandu, where people have better access to health care. Also, the prevalence of esotropia was only $0.24 \%$, and this could have resulted in the lower prevalence of strabismic amblyopia.

The prevalence of congenital color vision defect was $1.37 \%$. The condition was considered to be congenital red/green defect as there was no pathological cause accounting for this defect. A similar study from a western city of Nepal, Pokhara, has reported 1.87 $\%$ of children with color vision defect ${ }^{10}$, while in Kathmandu, the prevalence has been reported to be 2.2 \%. ${ }^{6}$ A study of school children from Karachi found the prevalence of color vision defect to be $1 \%{ }^{11}$. Among the male children the prevalence was $2.81 \%$. Studies have reported around $3.8 \%$ of male children with color vision defect. ${ }^{10,12}$ In some populations, the prevalence 
of colour defect in males has been reported to be as low as $1 \%{ }^{13}$. The wide variation in the prevalence of color vision defect in the different studies may be due to the differences in the sample population, ethnicity and methods used for examination.

Among the other disorders in our study, congenital disorders accounted for $0.40 \%$ of the total ocular morbidities, with government schools reporting 0.52 $\%$, which is two times that of the private schools 10.26 $\%)$. Similarly, Nepal et al reported $0.36 \%$ of children in government schools with congenital disorders. ${ }^{5}$ Another interesting pattern was seen in children with convergence insufficiency, with children from private schools reporting a significantly higher prevalence $(1.27 \%)$ than there at government schools $(0.57 \%)$. This could be due to the reported higher study load of the children of private schools.
We referred our students who required further investigation to our base hospital. However, very few with disorders such as pthisis bulbi came for the followup Hence we could not provide the details of the causes of some disorders.

\section{CONCLUSIONS}

Children of school-going age have significant ocular morbidity with myopia being the most common cause. The prevalence and patterns of morbidity including refractive error are not different in the government and private schools of Kathmandu. Research with a focus to evaluate the risk factors for refractive error is necessary to substantiate the difference in the pattern of ocular morbidity among school children of both government and private schools.

\section{REFERENCES}

1. Pizzarello L, Abiose A, Ffytche T, Duerksen R, Thulasiraj R, Taylor H, Faal H, Rao G, Kocur I, Resnikoff S. VISION 2020: The Right to Sight: a global initiative to eliminate avoidable blindness. Arch Ophthalmol, 2004;122(4):615-20.

2. Gilbert C, Foster A. Childhood blindness in the context of VISION 2020-the right to sight. Bull World Health Organ. 2001;79(3):227-32.

3. Steinkuller PG, Du L, Gilbert C, Foster A, Collins ML, Coats DK. Childhood blindness. J AAPOS. 1999;3(1):26-32.

4. Government of Nepal. Central Beuro of Statistics. Nepal Population Census. 2001.

5. Nepal BP, Koirala S, Adhikary S, Sharma AK. Ocular morbidity in schoolchildren in Kathmandu. Br J Ophthalmol. 2003;87(5):531-4.

6. Shrestha RK, Joshi MR, Ghising R, Pradhan P, Shakya S, Rizyal A. Ocular morbidity among children studying in private schools of Kathmandu valley: A prospective cross sectional study. Nepal Med Coll J. 2006;8(1):43-6.

7. Sapkota YD, Adhikari BN, Pokharel GP, Poudyal BK, Ellwein LB. The prevalence of visual impairment in school children of upper-middle socioeconomic status in Kathmandu. Ophthalmic Epidemiol. 2008;15(1):17-23.
8. Niroula DR, Saha CG. Study on the refractive errors of school going children of Pokhara city in Nepal. Kathmandu Univ Med J (KUMJ). 2009;7(25):67-72.

9. Thapa A. Does private school compitition improve public school performance? The case of Nepal. [PhD Thesis]. New York, NY 10027: COLUMBIA UNIVERSITY; 2011 [cited 2011 Jul 13]. Available from: http:/ / academiccommons.columbia. edu/catalog/ac:132305.

10. Niroula DR, Saha CG. The incidence of color blindness among some school children of Pokhara, Western Nepal. Nepal Med Coll J. 2010;12(1):48-50.

11. Alam H, Siddiqui MI, Jafri SI, Khan AS, Ahmed SI, Jafar M Prevalence of refractive error in school children of Karachi. J Pak Med Assoc. 2008;58(6):322-5.

12. Mahajan OP, Gogna RS. Study of colour blindness in school children. Indian J Physiol Pharmacol. 1977;21(1):59-62.

13. Norn M. Prevalence of congenital colour blindness among Inuit in East Greenland. Acta Ophthalmol Scand. 1997;75(2):206-9.

14. Gupta M, Gupta BP, Chauhan A, Bhardwaj A. Ocular morbidity prevalence among school children in Shimla, Himachal, North India. Indian J Ophthalmol. 2009;57(2):1338. 
15. Ajaiyeoba AI, Isawumi MA, Adeoye AO, Oluleye TS. Pattern of eye diseases and visual impairment among students in southwestern Nigeria. Int Ophthalmol. 2007;27(5):287-92.

16. 1Kalikivayi V, Naduvilath TJ, Bansal AK, Dandona L. Visual impairment in school children in southern India. Indian J Ophthalmol. 1997;45(2):129-34.

17. Pokharel GP, Negrel AD, Munoz SR, Ellwein LB. Refractive Error Study in Children: results from Mechi Zone, Nepal. Am J Ophthalmol. 2000;129(4):436-44.

18. Yekta A, Fotouhi A, Hashemi H, Dehghani C, Ostadimoghaddam H, Heravian J, Derakhshan A, Yekta R, Rezvan F, Behnia M, Khabazkhoob M. The prevalence of anisometropia, amblyopia and strabismus in schoolchildren of Shiraz, Iran. Strabismus. 2010;18(3):104-10.
19. Padhye AS, Khandekar R, Dharmadhikari S, Dole K, Gogate P, Deshpande M. Prevalence of uncorrected refractive error and other eye problems among urban and rural school children. Middle East Afr J Ophthalmol. 2009;16(2):69-74.

20. Shih YF, Chiang TH, Hsiao CK, Chen CJ, Hung PT, Lin LL. Comparing myopic progression of urban and rural Taiwanese schoolchildren. Jpn J Ophthalmol. 2010;54(5):44651.

21. Uzma N, Kumar BS, Khaja Mohinuddin Salar BM, Zafar MA, Reddy VD. A comparative clinical survey of the prevalence of refractive errors and eye diseases in urban and rural school children. Can J Ophthalmol. 2009;44(3):328-33. 